
Military Technical College Kobry El-Kobbah, Cairo, Egypt.

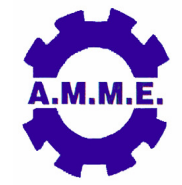

$15^{\text {th }}$ International Conference on Applied Mechanics and Mechanical Engineering.

\title{
EFFECT OF CEMENTLESS-ORTHOPAEDIC STEM DESIGN ON FEMUR STRESS-SHIELDING
}

\author{
M. E. Abo-Elnor*, A. E. Radi** and M. S. Abo-Elkhair*
}

\begin{abstract}
Total joint replacement has become a widely accepted treatment for many destructive joint diseases including osteoarthritis and severe pathologic fractures. Of total joint replacements, the hip is one of the most commonly replaced joints. Hip stem design varies from long to short, thick to thin and matt to smooth. In this study the effect of hip stem length on bone remodeling after surgery which is known as stress-shielding effect was analyzed using a finite element technique. Results show that stress-shielding introduced when using long-stem hip is much more than that of using short-stem hip in a total hip replacement for cementless implant.
\end{abstract}

\section{KEY WORDS}

Femur stress-shielding, Biomechanics, Femur modeling, Cement less hip implant.

* Egyptian Armed Forces.

** Professor of orthopaedics, Faculty of medicine, Ain-Shams Univ., Cairo, Egypt. 


\section{INTRODUCTION}

The total hip replacement is widely employed to treat bone disease or in fracture repair. Although this is a successful treatment, some problems associated with the prosthesis design remain unsolved. One of these problems is the loss of bone on the proximal femur due to the effect of stress-shielding [1], [2]. It can lead to fracture, loosening and reduction in the amount of bone available for a revision surgery.

The loosening mechanism is induced mainly by stress shielding which initiates the bone remodeling [3]. This makes the femur change its osseous density and distribution and therefore causes loosening of the joint stem. Stress shielding zone (Fig. 1) occurs due to the fact that stress is essentially carried by the stem, and consequently the stress on bone decreases relative to the intact femur (without prosthesis). The loss of bone is obviously related with the prosthesis design: a stiffer stem leads to a large amount of bone loss. This stiffness depends on stem dimensions as well as on stem material [4]. The dependence of the bone resorption on mechanical loads was described a century ago by Wolff's Law [5]. According to this law, the trabecular bone is able to self-adapt depending on the mechanical environment. In this work a numerical model using the finite element technique is carried out to analysis the effect of hip stem length on the level of stress-shielding.

\section{MATERIALS AND METHODS}

ANSYS finite element method software is used to establish an analysis model and simulate stress distribution of the femur bone when a cemented stem is used. Inventor, one of the advanced CAD modeling software, is used to generate two proposal models for a total hip with long stem and short stem to be used in the analysis of the effect of stem geometry on stress-shielding zone (Fig. 2). Advanced computed tomography (CT) data is used to create 3D CAD model of the femur bone.

The prosthesis is made of the titanium alloy Ti-6Al-4V, and the proximal area of the stem is coated with pure titanium powder applied in a plasma spray process under vacuum conditions (Plasma pore $($ )). The Plasma pore $® /$ titanium coating has an overall thickness of $0.35 \mathrm{~mm}$ and a micro-porosity of $35 \%$. The pore size varies between 50 and $200 \mu \mathrm{m}$. In the FE modeling a homogenous and isotropic material law $\left(E=110,000 \mathrm{~N} / \mathrm{mm}^{2}\right)$ is used for the prosthesis, and the coating is regarded by different friction coefficients in the contact region between bone and stem for the proximal and distal areas [6].

The CAD model concerning the trabecular bone zone, the cortical bone zone and the pours coating of the hip can be shown in Fig. 3 .

Stem material of hip joint is that of Ti-6Al-4V with Young's modulus $110000 \mathrm{MPa}$ and Poisson's ratio 0.3 . Material of the bone cement used is Ultrahigh- molecular-weight (UHMW) polyethylene with Young's modulus of $2280 \mathrm{MPa}$ and Poisson's ratio 0.3. The bone within the femur has a Young's modulus of $1300 \mathrm{MPa}$ and Poisson's ratio 0.28 [7]. It should be noted, however, that all materials were assumed to be isotropic in the present study. In reality both the fiber-reinforced epoxy of the composite femur 
and the cancellous and cortical bone are known to be anisotropic. The analysis is carried out in two regimes: one leg stand and (stair climbing). In the first regime, the abductor muscle force (1.754 BW inclined medially by $20^{\circ}$ from vertical), and the hip joint reaction force (2.1 BW, $16.6^{\circ}$ from vertical) [8]. Assuming a body weight of 71 $\mathrm{kg}$, the $\mathrm{x}, \mathrm{y}$, and $\mathrm{z}$ components of the joint reaction force are $(417.87,0,-1,401.71$ $\mathrm{N})$. The components of the force generated by the abductor muscle are $(-417.84,0$, $1,148 \mathrm{~N}),(\mathrm{x}, \mathrm{y}, \mathrm{z})$ shown in Fig. 4.

In the stair climbing regime, the peak flexion moment generated by a 71-kg man during stair climbing is 123.9 N.m in the sagittal plane and the adduction moment in the frontal plane is $25 \mathrm{~N} . \mathrm{m}$. There is no moment in the transverse plane. The load components of the force applied at the head of the femur with respect to the femoral coordinate system are then $(709.2,-600.8,-1,553.2 \mathrm{~N})$, with applied moments of $\mathrm{Mx}$ $=123.9$ N.m and $\mathrm{M} y=-2$ 5N.m [8].

For comparative analysis, the following parameters were considered and compared; stress in the bone around the hip. Completely bonded contact type was chosen as contact condition for cortical and cancellous bones contact surfaces, hip proximal/bone frictional coefficient is considered as 0.5 and hip distal/bone frictional coefficient is considered as 0.3 . A total hip replacement case was studied using a long hip stem and a short one in the same analysis platform as shown in Fig. 4, a refined mesh is used and the bottom boundary of the femur is set to be fixed resembles the knee connection (Fig. 5).

\section{RESULTS AND DISCUSSION}

The analysis was carried out firstly for a one leg stand in static loading condition, and then harmonic load is considered for normal walk case. Figures 6 and 7 show the equivalent stress distribution from the hip to the femur bone. The low stress zone of the long-stem hip is extended than that of the short-stem hip and hence the stressshield zone of the long-stem hip is greater than that of the short-stem hip. The conclusion can be drawn from Fig. 8, which resemble the total deformation over the analyzed model, the total deformation of the short-stem hip is greater than that of long-stem hip which means low strain distribution over the femur top when using the long-stem hip and hence weak bone remolding in this zone after surgery.

A dynamic analysis shows the effect of walk cycle repetition on stress distribution for both long-stem and short-stem hip, Fig. 9. The proximal part of the femur is subjected to higher stress when using short-stem hip than that in long-stem hip hence the extended distribution of the stress-shield zone of the long-stem hip over the one of short-stem hip.

Second load regime (stair climbing) is carried out to activate the tensional component of the applied force in the analysis as a result of patient stairs climb or ramp walking. Figure 10 shows the global analysis setup and applied loads. Stress distribution over the femur bone is shown in Fig. 10 which reveals a higher stresses acting on the bone when using short-stem hip than that when using long-stem hip. 


\section{CONCLUSIONS}

The finite element analysis conducted in this work reveals the effect of stem geometry (length) on the creation of what so called stress-shielding of the femur bone after surgery. Regardless of the ease of implant of a long-stem hip; the analysis shows that using short-stem hip, in total hip replacement, is better than using long-stem hip from the stress-shielding point of view. Applying torsion stress to the femur after surgery as a result of patient practice may decreases the possibility of stress-shield zone extension over the femur bone and hence allows condense bone remodeling around the implant and long-time strengthen the bone after surgery. As a conclusion, using of short-stem hip reduces the stress-shielding zone and hence increases bone remolding after surgery.

\section{REFERENCES}

[1] J. D. Bobyn, A. H. Glassman, et al , "The Effect of Stem stiffness on Femoral Bone Resorption after Canine Porous-Coated Total Hip Arthroplasty", Clinical Orthopaedics and Related Research Vol. 261, PP. 196-213, 1990.

[2] B. Rietbergen, R. Huiskes, et al, "The Mechanism of Bone Remodeling and Resorption around Press-Fitted THA Stems", J. Biomechanics Vol. 26, No 4/5, PP. 369-382, 1993.

[3] CHEUNG-HWA HSU, "TRADE-OFF DESIGN OF TOTAL HIP PROSTHESIS", Biomed Eng Appl Basis Comm Vol. 17, PP. 319-323, 2005.

[4] H. Weinans, R. Huiskes and H. J. Grootenboer, "Effects of Material Properties of Femoral Hip Components on Bone Remodeling", J. Orthop. Res. Vol. 10, No 6, PP. 845-853, 1992.

[5] J. Wolff, "The law of Bone Remodelling", Translated by Maquet P. and Furlong R. Springer, Berlin, (1986).

[6] Bernd-Arno Behrens, et al, "Numerical investigations on the strain-adaptive bone remodelling in the periprosthetic femur: Influence of the boundary conditions", BioMedical Engineering OnLine, Vol. 8, No 7, 2009.

[7] Fagan, M. J., and Lee, A. J. C., "Materials Selection in the Design of the Femoral Component of Cemented Total Hip Replacement", Clin. Mater. , PP.151-167, 1986.

[8] Frances B. Biegler, Jeffrey D. Reuben, et al, "Effect of Porous Coating and Loading Conditions on Total Hip Femoral Stem Stability", the Journal of Arthroplasty Vol. 10 No. 6, 1995. 


\section{FIGURES:}
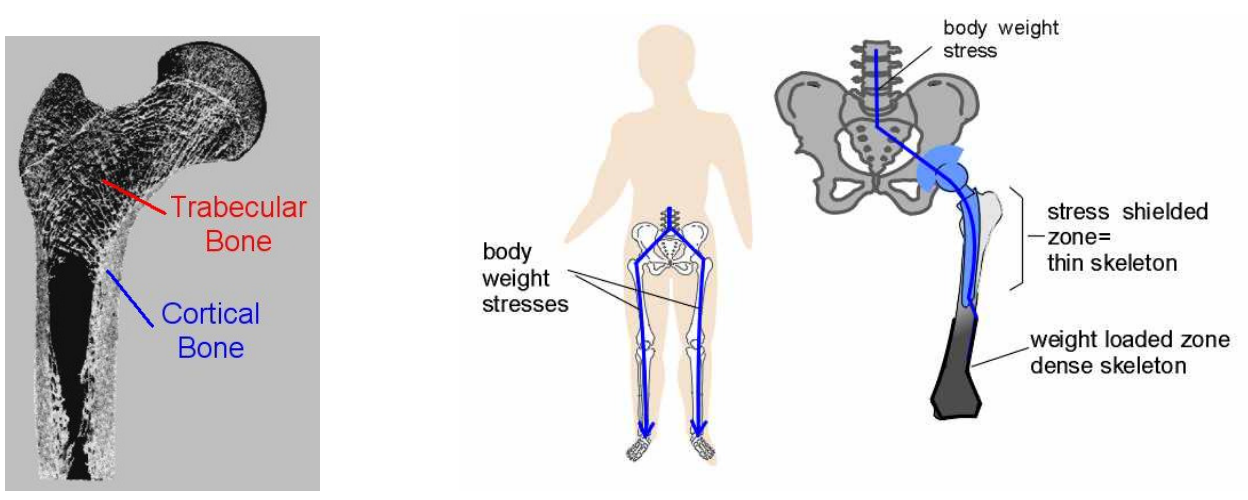

Fig. 1. Femur stress-shielding zone.

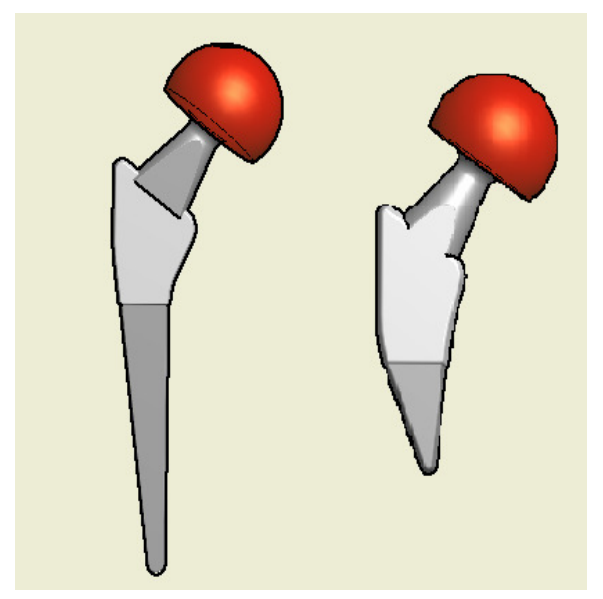

Fig. 2. Long-stem (left) and Short-stem total hip replacement implant.

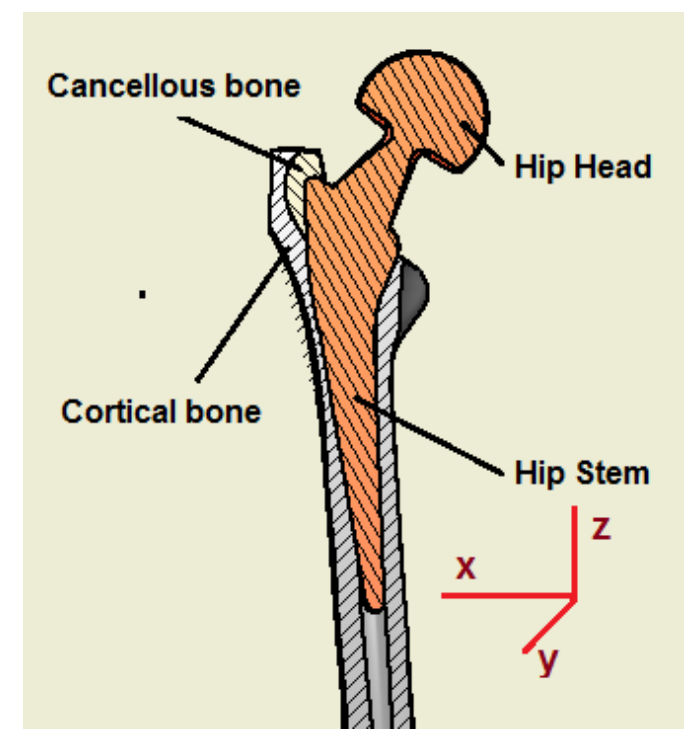

Fig. 3. Section view in the proposed model. 
A: One Leg Stand

Static Structural

Time: 1.5

9/20/2010 10:09 PM

A Fixed Support

B Force: $1460.8 \mathrm{~N}$

C Force 2: $1460.8 \mathrm{~N}$

D Force 3: $1221.4 \mathrm{~N}$

E Force 4: $1221.4 \mathrm{~N}$
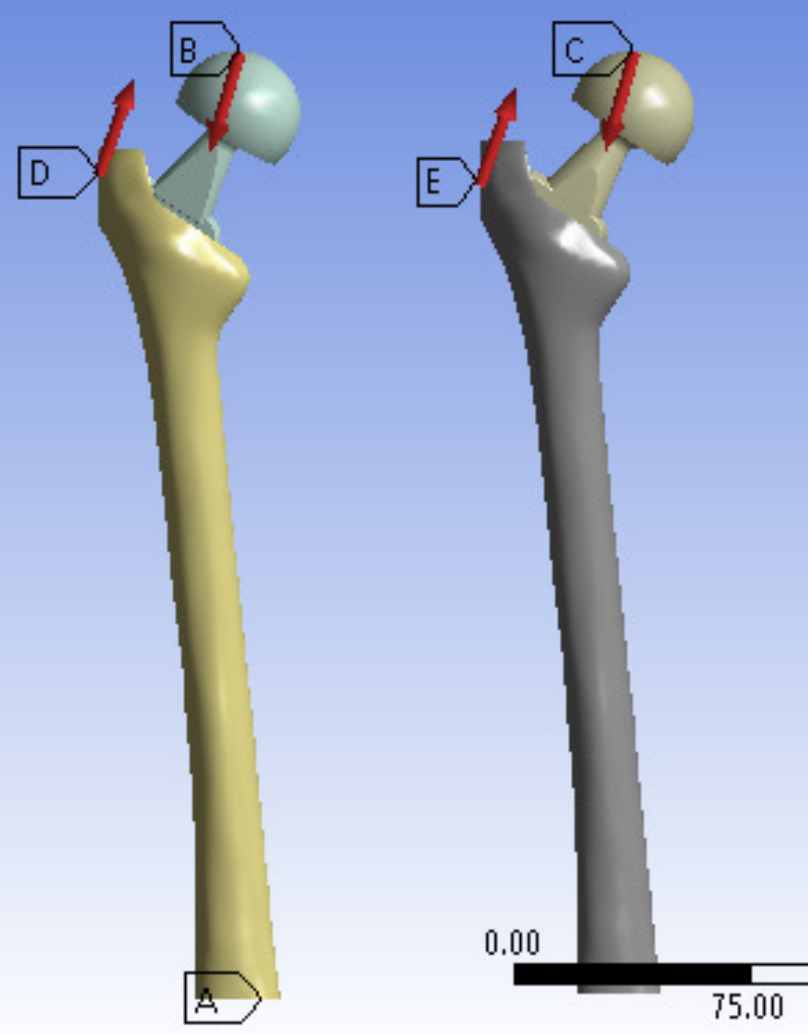

Fig. 4. Analysis setup and boundary conditions for one-leg stand.
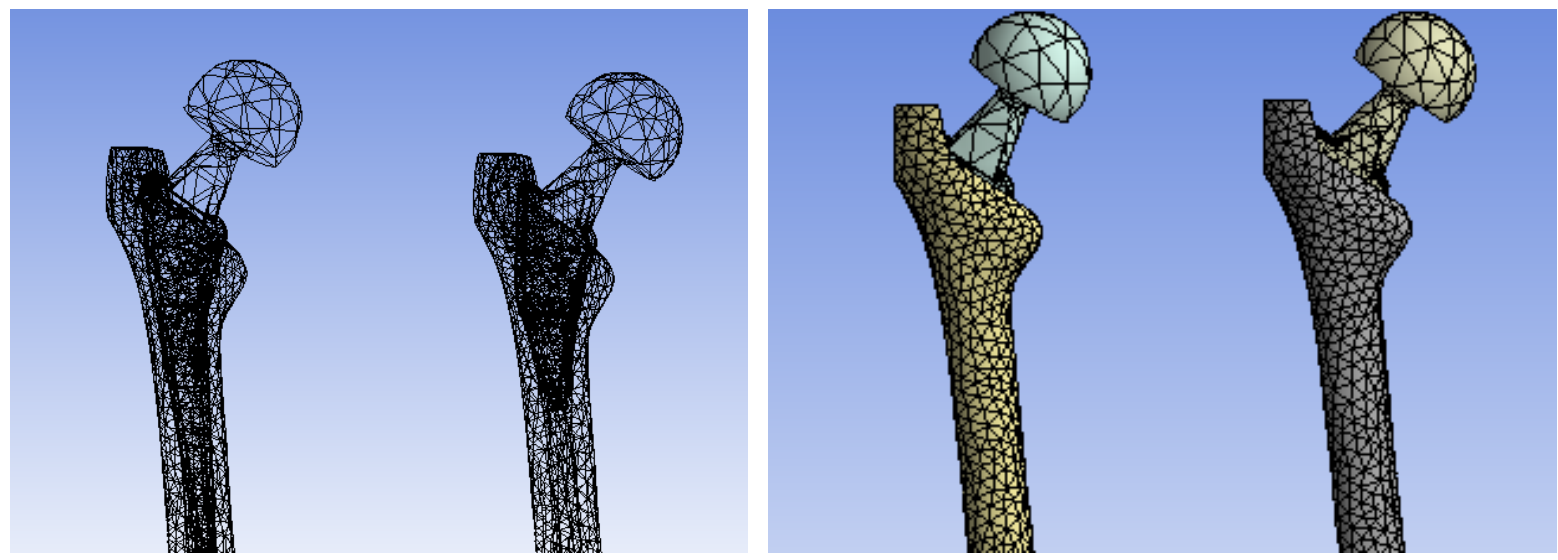

Fig. 5. Refined mesh for long-stem hip and short-stem hip in wire frame (left) and shaded (right). 


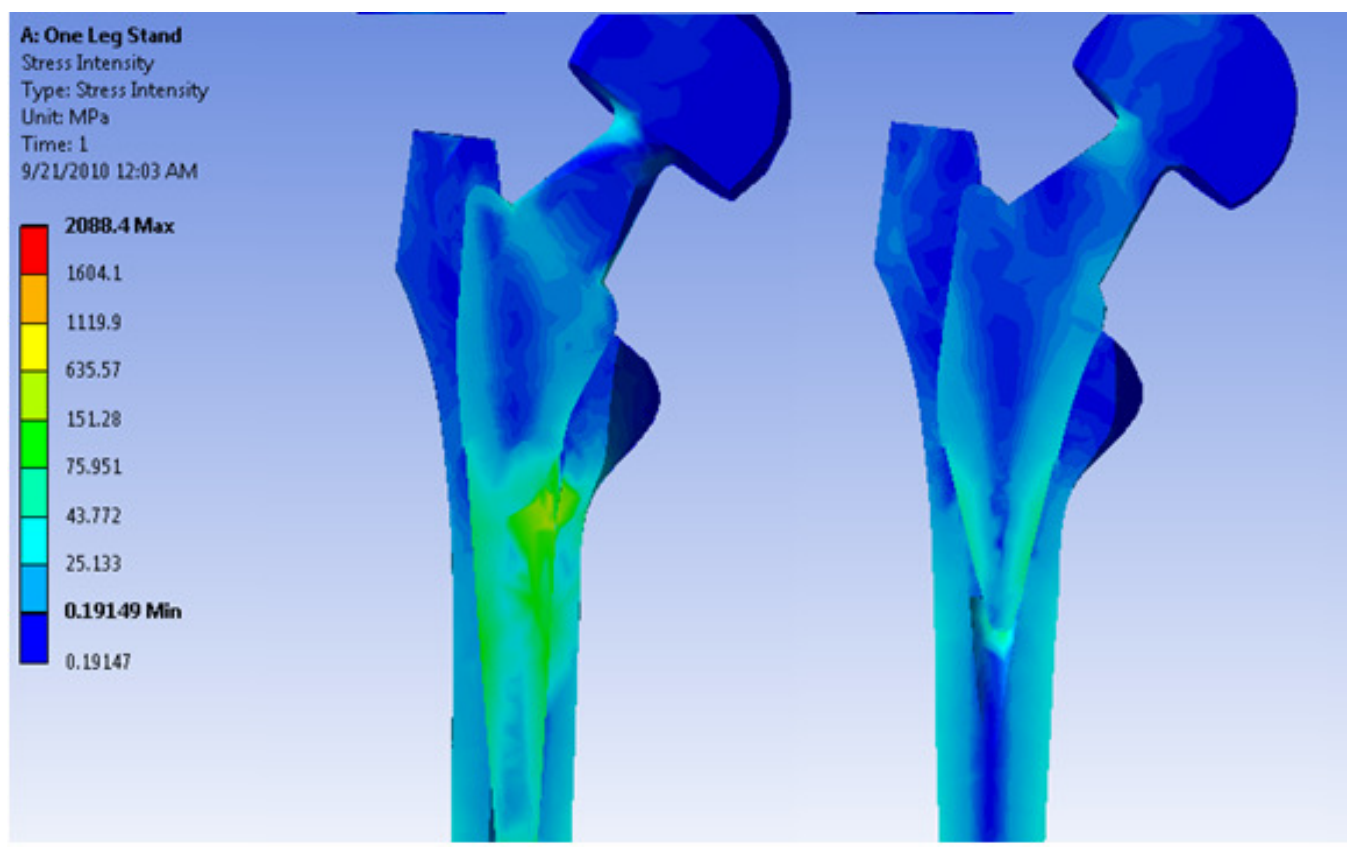

Fig. 6. Stress distribution on long-stem hip (left) and short-stem hip (right) in section view.

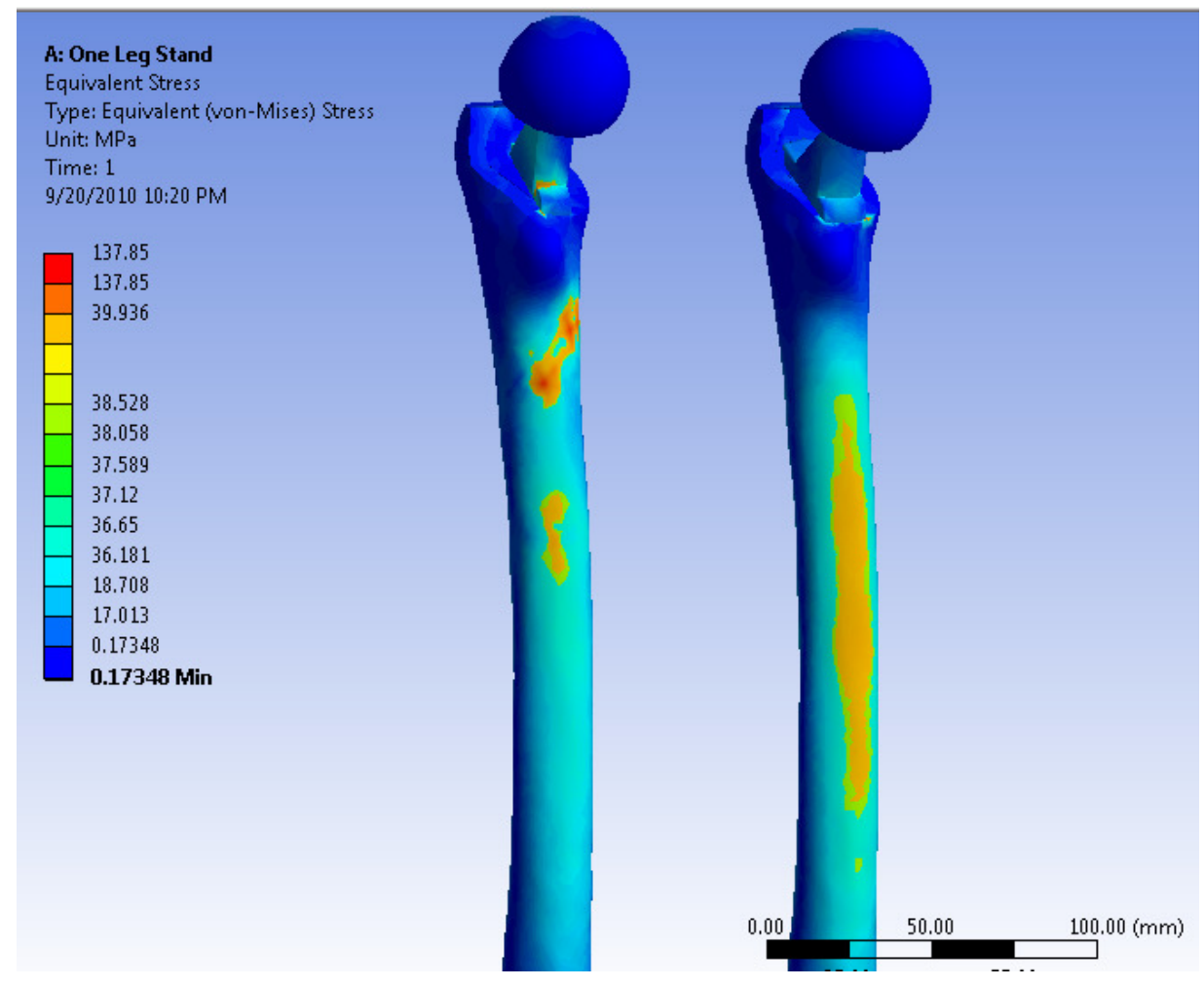

Fig. 7. Stress distribution on long-stem hip (left) and short-stem hip (right). 


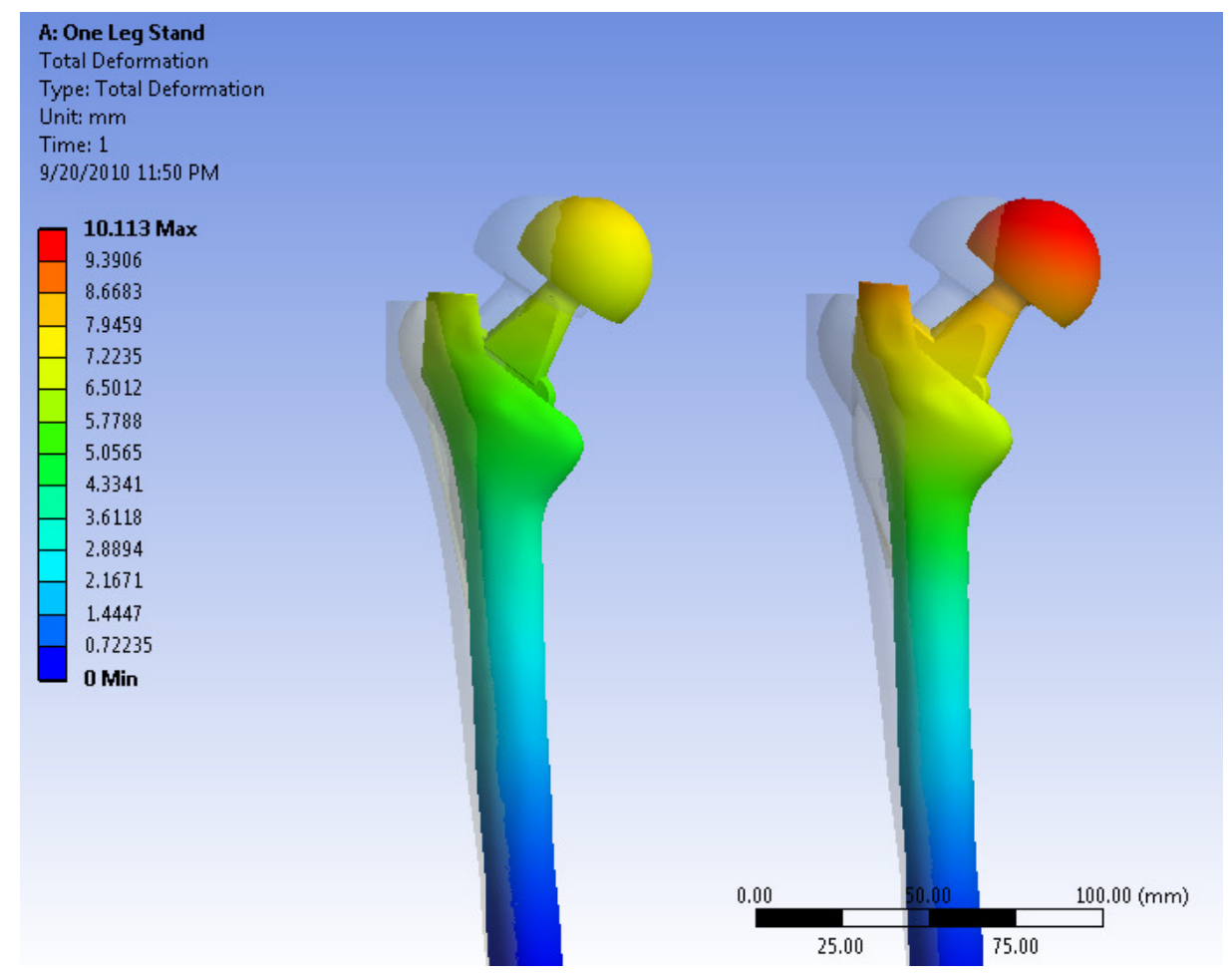

Fig. 8. Total deformation on long-stem hip (left) and short-stem hip (right).

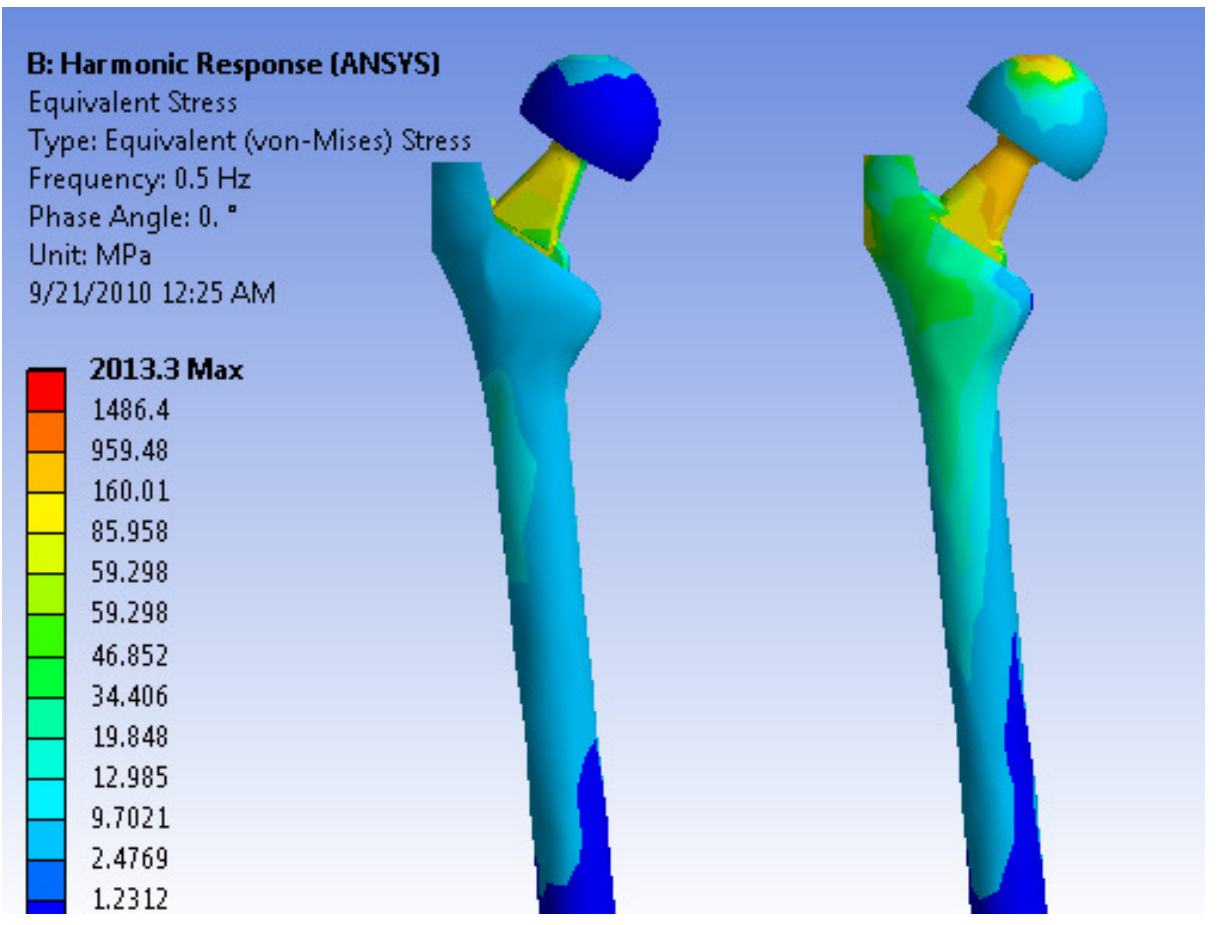

Fig. 9. Stress distribution on long-stem hip (left) and short-stem hip (right) for dynamic analysis. 


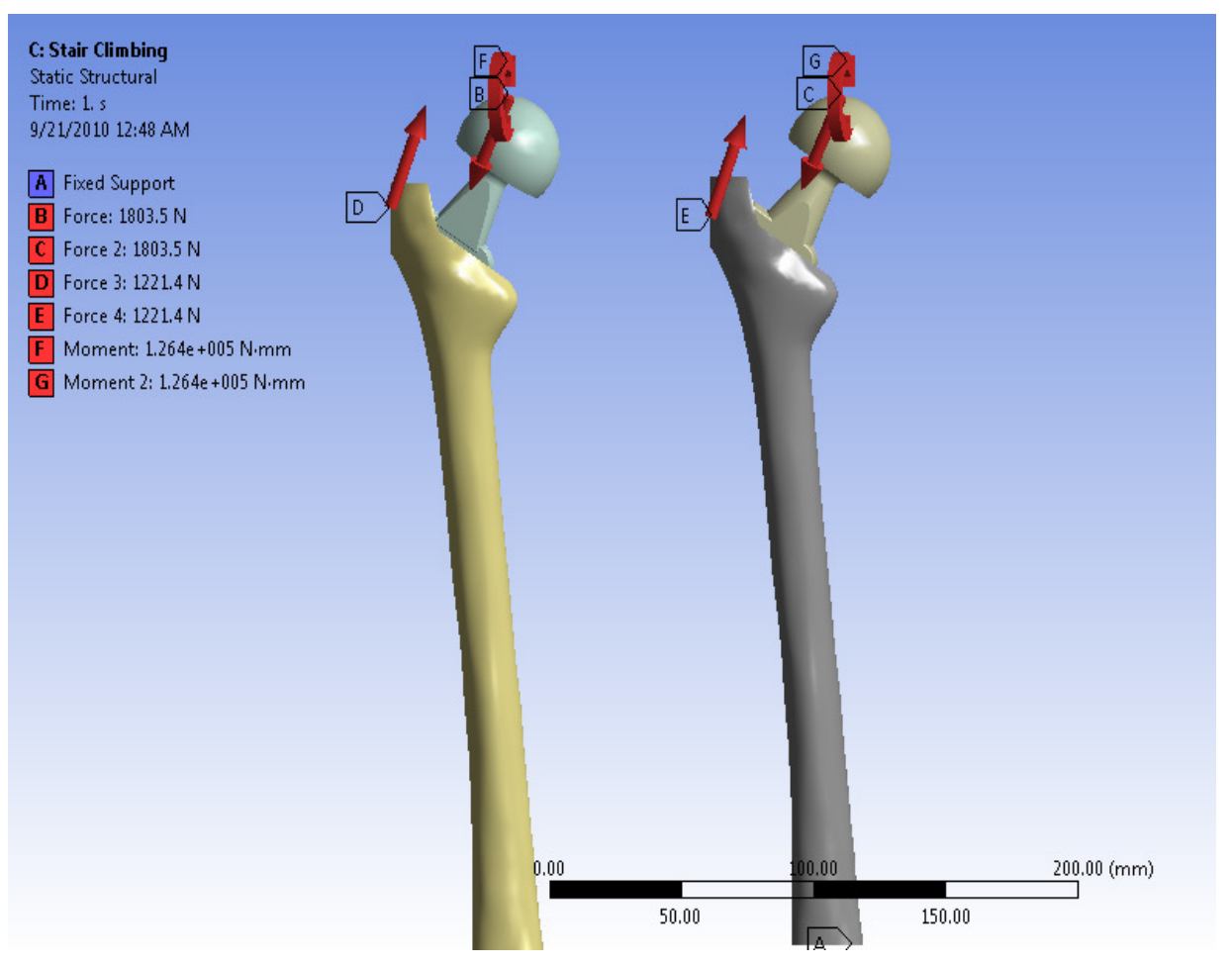

Fig. 10. Analysis setup and boundary conditions for stair climbing.

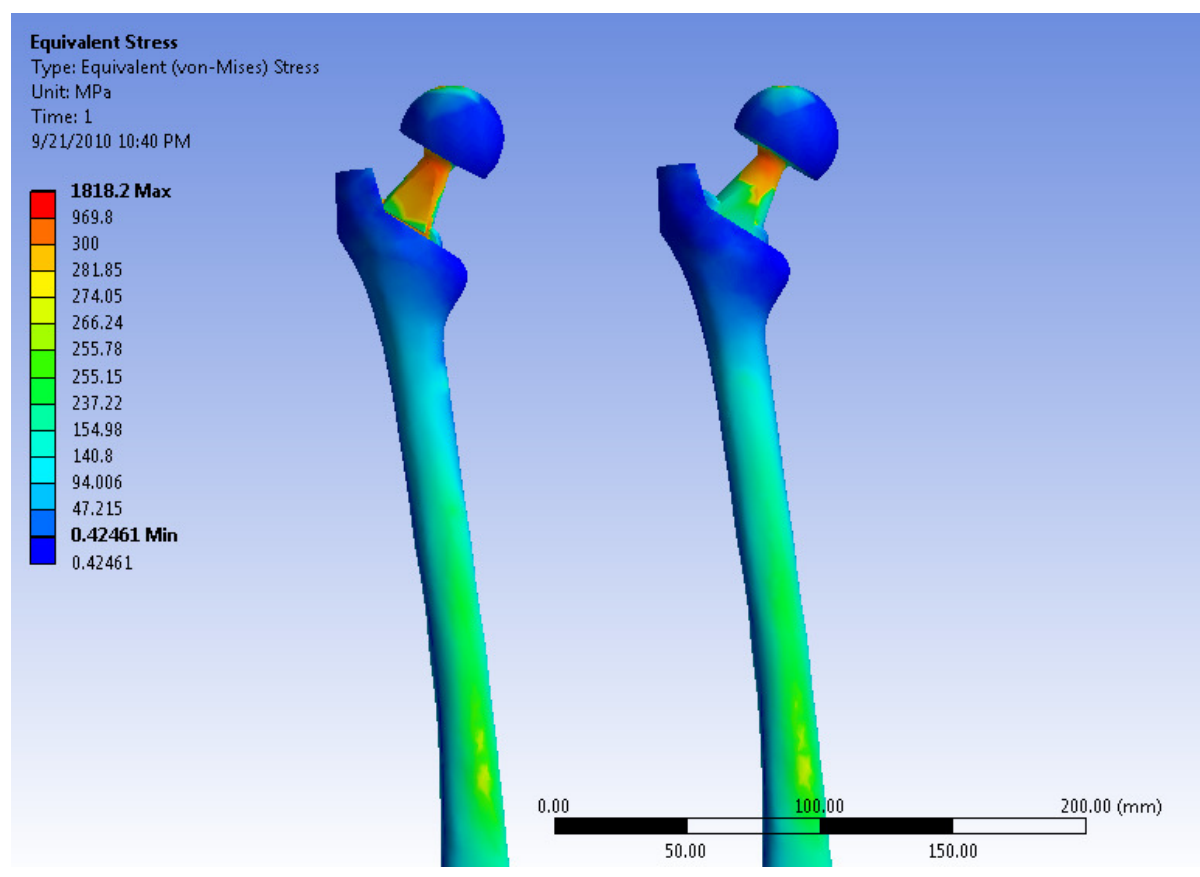

Fig. 11. Stress distribution on long-stem hip (left) and short-stem hip (right) for stair climbing. 